\title{
ANALISIS EFEKTIVITAS PEMUNGUTAN PAJAK HOTEL DAN PAJAK RESTORAN SERTA KONTRIBUSI TERHADAP PENDAPATAN ASLI DAERAH KOTA TOMOHON
}

\author{
Ni Luh Putu Anggraini ${ }^{1}$, Jantje J. Tinangon ${ }^{2}$, Stanley Kho Walandouw ${ }^{3}$ \\ ${ }^{1,2,3}$ Jurusan Akuntansi, Fakultas Ekonomi dan Bisnis, Universitas Sam Ratulangi, Jl. Kampus Bahu, Manado, \\ 95115, Indonesia \\ E-mail : nilputuanggraini@yahoo.com
}

\begin{abstract}
The Local Genuine Income (PAD) is a income earned by the region through regional taxes, regional retribution, and management of regional wealth for the development of the region. The hotel and restaurant tax is the local tax that has the potential to improve local revenue due to the supporting component from tourism sector Tomohon City which keep growing. The purpose of this study is to determine the level of effectiveness of hotel tax and restaurant tax collection in Tomohon City in 2013-2017 and to find out the contribution given by hotel tax and restaurant tax on the receipt of original revenue in the city of Tomohon in 2013-2017. The method used in this thesis is descriptive method, that is by analysing data and then drawing conclusion from the results of the study and the type of research used is descriptive qualitative. The results of this study indicate that the effectiveness of hotel tax collection in 2013-2017 has been effective with an average of 90,40\%, while the effectiveness of restaurant tax is very effective with an average of $132,94 \%$. The contribution given by the hotel tax to the local revenue of Tomohon city in 2013-2017 is still very lacking with an average of 0,60\%, while the contribution given by the restaurant tax is not good with an average of $12,33 \%$.
\end{abstract}

Keywords : Hotel Tax, Restaurant Tax, Contribution, Effectiveness, Local Genuine Income

\section{PENDAHULUAN}

Pajak adalah kewajiban rakyat kepada negara yang merupakan bentuk kontribusi masyarakat untuk membangun tanah air dan negara. Dalam pemungutan dan pengenaannya pajak bersifat memaksa tapi tidak semena-mena karena terdapat aturan yang diberlakukan oleh pemerintah. Pajak tidak hanya terdapat di Indonesia, hampir seluruh Negara menerapkan sistem perpajakan. Tetapi, sistem yang diterapkan berbeda-beda antara negara satu dengan negara lainnya tetapi memiliki tujuan yang sama yaitu menuju pada kemakmuran rakyat.

Seiring berkembangnya komponen pendukung sektor pariwisata dan semakin diperhatikannya sektor jasa dan kebijakan dalam peningkatan pembangunan daerah, mempengaruhi penerimaan pajak hotel dan pajak restoran yang menunjukkan presentase yang semakin baik dari tahun sebelumnya. Saat ini pemerintah provinsi Sulawesi Utara sedang gencar-gencarnya meningkatkan sektor pariwisata dengan dibukanya penerbangan langsung atau charter flight dari beberapa kota di Tiongkok. Hal ini dibuktikan dengan banyaknya wisatawan mancanegara asal Tiongkok yang datang berlibur dan Kota Tomohon yang dijuluki kota bunga yang juga merupakan salah satu kota yang wajib dikunjungi para wisatawan karena memiliki banyak objek wisata.

Akibat melonjaknya wisatawan mancanegara jumlah hotel dan restoran di Kota Tomohon beberapa tahun belakangan ini meningkat, oleh karena itu perlu dilakukan perhitungan pemungutan pajak daerah yang update dan akurat. Analisis efektivitas Pajak Hotel dan Pajak Restoran mutlak diperlukan untuk mengukur dan mengevaluasi sejauh mana pelaksanaan pemungutan Pajak Hotel dan Pajak Restoran di Kota Tomohon. Efektivitas dan 
Kontribusi yang diberikan Pajak Hotel dan Pajak Restoran diharapkan mampu meningkatkan Pendapatan Asli Daerah (PAD) Kota Tomohon.

\section{TINJAUAN PUSTAKA}

Definisi Akuntansi. Simamora (2013:1) menyatakan akuntansi sebagai proses pengumpulan, pengklasifikasian, pencatatan yang menghasilkan laporan keuangan perusahaan yang digunakan oleh pihak yang berkepentingan baik pihak diluar perusahaan ataupun didalam perusahaan yang dapat mempengaruhi pengambilan keputusan.

Definisi Akuntansi Perpajakan. Akuntansi dimulai dengan adanya transaksi yang bersifat keuangan, yaitu peristiwa yang dapat berdampak terhadap posisi keuangan suatu perusahaan. Tranksaksi inilah yang menjadi alasan pemerintah untuk mengeluarkan peraturan perpajakan agar dapat melakukan pemungutan pajak untuk membiayai pembangunan negara. Dengan adanya titik ketersinggungan antara akuntansi dan pajak, yaitu transaksi, perusahaan menerapkan akuntansi yang sudah sesuai dengan peraturan pajak yang berlaku, yang disebut akuntansi pajak (Lubis, 2015:2).

\section{Konsep Pajak}

Definisi Pajak. Sari (2013:35) menyatakan pajak adalah pembayaran kewajiban rakyat untuk negara yang sifatnya memaksa dan digunakan untuk membiayai pengeluaran rumah tangga negara yang dibebankan pada pendapatan kekayaan seseorang.

Fungsi Pajak. Pajak memiliki 2 fungsi yang utama (Mardiasmo,2013:6) yaitu; (1) Fungsi Finansial, (2) Fungsi Mengatur.

Tata Cara Pemungutan Pajak. Pemungutan pajak dapat dilakukan berdasarkan tiga stelsel (Mardiasmo,2013:6) yaitu; (1) Stelsel Nyata (riel stelsel), (2) Stelsel Anggapan (fictieve stelsel,) (3) Stelsel Campuran.

Pengelompokan Pajak. Menurut Mardiasmo (2013:5) pajak dapat dibedakan atas beberapa cara pembedaan, yaitu berdasarkan golongan, wewenang pemungut, maupun sifatnya.

Sistem Pemungutan Pajak. Mardiasmo (2013:7) menyatakan bahwa system pemungutan pajak terbagi tiga, yaitu: (1) Official Assessment System, (2) Self Assessment System, (3) With Holding System.

Asas Pemungutan Pajak. Pemungutan pajak didasarkan pada asas-asas tertentu yang merupakan pedoman bagi pemerintah dalam melakukan pemungutan pajak dari rakyatnya yang disesuaikan dengan Undang-Undang yaitu, asas domisili atau berdasarkan tempat tinggal rakyatnya, asas sumber penghasilan yang didapatkan dan asas kebangsaan.

Syarat Pemungutan Pajak. Syarat dalam pemungutan pajak diperlukan guna menjadi landasan pemerintah agar memberlakukan pemungutan pajak yang adil dan tidak menimbulkan kendala atau perlawanan. Menurut Mardiasmo (2013:7) syarat dalam pemungutan pajak yaitu: (1) harus adil, (2) harus berdasarkan Undang-Undang, (3) tidak menganggu perekonomian (syarat ekonomis), (4) harus efisien (syarat finansil), (5) sistem pemungutan harus sederhana.

Prinsip Pemungutan Pajak. Era yang dikutip oleh Rooy (2016), ada empat jenis prinsip pemungutan pajak, yaitu: (1) Prinsip Fiskal,(2) Prinsip Ekonomi,(3) Prinsip Etika,(4) Prinsip Administratif.

Konsep Pajak Daerah. Undang-Undang Nomor 28 Tahun 2009 tentang Pajak Daerah dan Retribusi Daerah Daerah: "Pajak Daerah yang selanjutnya disebut pajak, adalah kontribusi wajib kepada daerah yang terutang oleh orang pribadi atau badan yang bersifat memaksa berdasarkan undang-undang, dengan tidak mendapatkan imbalan secara langsung dan digunakan untuk keperluan Daerah bagi sebesar-besarnya kemakmuran rakyat". Ciri-ciri pajak daerah adalah pajak yang asli didapatkan dari daerah tersebut, dipungut berdasarkan peraturan hukum dan dipergunakan untuk membiayai pembangunan daerah. 
Jenis-Jenis Pajak Daerah. Sesuai dengan pembagian administrasi daerah, menurut UndangUndang Nomor 28 Tahun 2009, Pajak Daerah dapat digolongkan menjadi dua macam yaitu, Pajak Provinsi yang terdiri dari 5 (Lima) jenis pajak dan Pajak Kota/Kabupaten yang terdiri dari 11 (sebelas) jenis pajak yang di dalamnya termasuk Pajak Hotel dan Pajak Restoran.

\section{Pajak Hotel}

Konsep Pajak Hotel. Berdasarkan Undang-Undang Nomor 28 tahun 2009 tentang Pajak Daerah dan Retribusi Daerah yang dimaksud pajak hotel adalah pajak yang dikenakan atas pelayanan yang disediakan oleh pihak hotel. Objek pajak hotel adalah setiap pelayanan yang diberikan pihak hotel dengan pembayaran seperti fasilitas penginapan, fasilitas olahraga dan pelayanan penunjang lainnya. Subjek pajak hotel adalah orang pribadi atau badan yang menggunakan menerima pelayanan yang disediakan pihak hotel dan melakukan pembayaran. Wajib pajak hotel adalah orang pribadi atau badan yang mendirikan usaha hotel. Berdasarkan PERDA Kota Tomohon No.7 Tahun 2012 tentang Pajak Daerah tarif pajak hotel ditetapkan sebesar $10 \%$ (sepuluh persen).

\section{Pajak Restoran}

Konsep Pajak Restoran. Menurut Undang-Undang Nomor 28 tahun 2009 tentang Pajak Daerah dan Retribusi Daerah, pajak restoran adalah pajak yang dikenakan atas pelayanan yang disediakan oleh pihak restoran. Yang dimaksud dengan restoran adalah usaha yang menyediakan makanan dan minuman dan dipungut bayaran. Sedangkan wajib pajak restoran adalah orang pribadi atau badan yang mengusahakan restoran. Berdasarkan PERDA Kota Tomohon No.7 Tahun 2012 tentang Pajak Daerah tarif pajak restoran ditetapkan sebesar 10\% (sepuluh persen).

Konsep Efektivitas. Mahmudi (2015:86) mendefinisikan bahwa efektivitas merupakan hubungan antara hasil yang diterapkan dengan hasil yang sesungguhnya dicapai.

Konsep Kontribusi. Kontribusi merupakan sumbangsih untuk pemerintahan yang dipergunakan untuk pembangunan daerah ataupun negara yang diberikan oleh suatu sistem pajak.

Pendapatan Asli Daerah (PAD). Pendapatan Asli Daerah dalam Undang-Undang No. 28 Tahun 2009 merupakan pendapatan yang didapatkan daerah yang bersangkutan melalui pajak daerah, retribusi daerah, dan pengelolaan kekayaan daerah tersebut yang dipergunakan untuk pembangunan daerah. Sejak adanya otonomi daerah, setiap daerah harus memanfaatkan kewangan yang dimiliki untuk menggali potensi daerah secara optimal agar dapat mendukung keuangan daerah dan digunakan untuk penyelenggaraan dan pembiayaan didaerah.

Penelitian Terdahulu. Sisdayani (2013) dalam penelitian berjudul Penilaian Kinerja Atas Penerimaan Pajak Hotel Dan Pajak Restoran Di Dinas Pendapatan Daerah Kabupaten Karangasem dengan hasil penelitian menunjukkan kinerja dari Dinas Pendapatan Daerah Kabupaten Karangasem atas penerimaan yang diterima daerah dari pajak hotel dan pajak restoran adalah ekonomis, sangat efisien, sangat efektif. Candrasari (2015) penelitian yang berjudul Kontribusi Pajak Hotel dan Pajak Restoran Terhadap Peningkatan Pendapatan Asli Daerah Kota Surabaya dengan hasil penelitian menunjukan potensi pajak tahun 2010-2014 mengalami peningkatan. Tapi kontribusi dari tahun 2010-2014 terus menurun. Puspita (2016) dengan penelitian yang berjudul Analisis Efektivitas Penerimaan Pajak Restoran, Pajak Hotel Dan Pajak Penerangan Jalan Dalam Meningkatkan PAD Kota Depok. Hasil penelitian menunjukan efektivitas dari pajak restoran sebesar 112,31\% dengan kategori sangat efektif, pajak hotel 119,95\% dan pajak penerangan jalan 107,48\%. 


\section{METODE PENELITIAN}

Jenis Penelitian. Jenis penelitian yang digunakan adalah penelitian kualitatif deskriptif. Jenis kualitatif deskriptif adalah jenis penelitian yang membuat gambaran atau menganalisis suatu situasi lalu menarik kesimpulan. Data yang digunakan hanya terbatas pada data efektivitas dan kontribusi pajak hotel dan pajak restoran serta penerimaan Pendapatan Asli Daerah (PAD) Kota Tomohon dari tahun 2013-2017.

Tempat dan Waktu Penelitian. Penelitian ini dilakukan pada Badan Keuangan Daerah Kota Tomohon di Jl. Slanag Kolongan Kota Tomohon. Penelitian ini dilaksanakan mulai bulan April 2018 sampai bulan Agustus 2018.

\section{Jenis Dan Sumber Data}

Jenis Data. Data dalam penelitian ini adalah data kualitatif yang berupa data target dan realisasi pajak hotel dan pajak restoran serta PAD Kota Tomohon tahun 2013-2017.

Sumber Data. Sumber data yang digunakan dalam penelitian ini adalah data primer, berupa catatan hasil wawancara dan data penerimaan pajak hotel dan pajak restoran serta PAD Kota Tomohon tahun 2013-2017.

\section{Metode Pengumpulan Data}

a. Dokumentasi. Laporan target serta realisasi Pajak Hotel, Pajak Restoran dan PAD Kota Tomohon.

b. Teknik wawancara. Penelitian ini melakukan wawancara berstruktur dengan Kepala Bidang Pajak Badan Keuangan Daerah Kota Tomohon untuk memperoleh informasi mengenai kendala-kendala yang mempengaruhi pemungutan pajak hotel dan pajak restoran serta sejarah dan struktur instansi.

Metode Analisis. Metode analisis yang digunakan dalam penelitian ini adalah deskriptif. Dimana, metode yang digunakan untuk membuat gambaran atau menganalisis suatu hasil penelitian tetapi tidak digunakan untuk membuat kesimpulan yang lebih luas (Sujarweni, 2014: 46). Penulis menguraikan data penerimaan pajak hotel, pajak restoran dan PAD Kota Tomohon, serta hasil wawancara yang dilaksanakan pada Badan Keuangan Daerah Kota Tomohon kemudian diolah oleh penulis sehingga didapatkan efektivitas dan kontribusi yang diberikan sehingga dapat mengambil keputusan secara sitematis.

\section{HASIL PENELITIAN DAN PEMBAHASAN \\ 4.1. Hasil Penelitian \\ Target dan Realisasi Pajak Hotel Kota Tomohon Tahun 2013-2017}

Tabel 1. Target dan Realisasi Pajak Hotel Kota Tomohon Tahun 2013-2017

\begin{tabular}{crr}
\hline Tahun & Target (Rp) & Realisasi (Rp) \\
\hline 2013 & $150.975 .000,00$ & $85.216 .000,00$ \\
2014 & $324.365 .000,00$ & $88.875 .750,00$ \\
2015 & $96.000 .000,00$ & $111.957 .371,00$ \\
2016 & $130.500 .000,00$ & $174.877 .932,00$ \\
2017 & $200.500 .000,00$ & $235.739 .188,00$ \\
\hline
\end{tabular}

Sumber : Data Badan Keuangan Daerah Kota Tomohon, 2018.

Berdasarkan Tabel 1 menunjukkan bahwa target penerimaan Pajak Hotel Kota Tomohon tahun 2013 Rp150.975.000,00 dan realisasi Rp85.216.000,00. Pada tahun 2014 target Rp324.365.000,00 dan realisasi Rp88.875.750,00. Tahun 2015 target Rp96.000.000,00 dan realisasi Rp111.957.371,00. Di tahun 2016 target Rp130.500.000,00 dan realisasi Rp174.877.932,00. Tahun 2017 target Rp200.500.000,00 dan realisasi Rp235.739.188,00. 
Target dan Realisasi Pajak Restoran Kota Tomohon Tahun 2013-2017

Tabel 2. Target dan Realisasi Pajak Restoran Kota Tomohon Tahun 2013-2017

\begin{tabular}{crr}
\hline Tahun & Target $(\mathbf{R p )}$ & Realisasi (Rp) \\
\hline 2013 & $1.175 .000 .000,00$ & $1.484 .959 .553,00$ \\
2014 & $1.227 .600 .000,00$ & $2.140 .442 .860,00$ \\
2015 & $1.858 .600 .000,00$ & $3.019 .391 .763,00$ \\
2016 & $3.087 .232 .000,00$ & $3.451 .597 .137,00$ \\
2017 & $3.647 .232 .000,00$ & $3.263 .185 .687,00$ \\
\hline
\end{tabular}

Sumber : Data Badan Keuangan Daerah Kota Tomohon, 2018.

Berdasarkan Tabel 2 menunjukkan bahwa target penerimaan Pajak Restoran Kota Tomohon tahun $2013 \mathrm{Rp} 1.175 .000 .000,00$ dan realisasi Rp1.484.959.553,00. Pada tahun 2014 target Rp1.227.600.000,00 dan realisasi Rp2.140.442.860,00. Tahun 2015 target Rp1.858.600.000,00 dan realisasi Rp3.019.391.763,00. Di tahun 2016 target Rp3.087.232.000,00 dan realisasi Rp3.451.597.137,00. Tahun 2017 target Rp3.647.232.000,00 dan realisasi Rp3.263.185.687,00.

Target dan Realisasi Penerimaan PAD Kota Tomohon Tahun 2013-2017

Tabel 3. Target dan Realisasi Penerimaan PAD Tahun 2013-2017

\begin{tabular}{crr}
\hline Tahun & Target $(\mathbf{R p )}$ & Realisasi (Rp) \\
\hline 2013 & $12.700 .975 .000,00$ & $13.945 .339 .275,00$ \\
2014 & $21.206 .931 .368,00$ & $17.378 .569 .341,00$ \\
2015 & $21.638 .321 .384,00$ & $20.688 .883 .680,00$ \\
2016 & $26.383 .643 .000,00$ & $26.321 .670 .690,00$ \\
2017 & $31.926 .132 .000,00$ & $29.543 .783 .344,00$ \\
\hline
\end{tabular}

Sumber : Data Badan Keuangan Daerah Kota Tomohon, 2018.

Berdasarkan Tabel 3 menunjukkan bahwa target penerimaan PAD Kota Tomohon tahun 2013 Rp12.700.975.000,00 dan realisasi Rp13.945.339.275,00. Pada tahun 2014 target Rp21.206.931.368,00 dan realisasi Rp17.378.569.341,00. Tahun 2015 target $\mathrm{Rp} 21.638 .321 .384,00$ dan realisasi $\mathrm{Rp20.688.883.680,00.} \mathrm{Di}$ tahun 2016 target Rp26.383.643.000,00 dan realisasi Rp26.321.670.690,00. Tahun 2017 target Rp31.926.132.000,00 dan realisasi Rp29.543.783.344,00.

\subsection{Pembahasan}

Efektivitas Pemungutan Pajak Hotel Kota Tomohon Tahun 2013-2017

Tabel 4. Efektivitas Pemungutan Pajak Hotel Kota Tomohon Tahun 2013-2017

\begin{tabular}{crrrr}
\hline Tahun & \multicolumn{1}{c}{$\begin{array}{c}\text { Target } \\
(\mathbf{R p})\end{array}$} & $\begin{array}{c}\text { Realisasi } \\
(\mathbf{R p})\end{array}$ & $\begin{array}{c}\text { Persentase } \\
(\boldsymbol{\%})\end{array}$ & \multicolumn{1}{c}{ Kriteria } \\
\hline 2013 & $150.975 .000,00$ & $85.216 .000,00$ & 56,44 & Tidak Efektif \\
2014 & $324.365 .000,00$ & $88.875 .750,00$ & 27,40 & Tidak Efektif \\
2015 & $96.000 .000,00$ & $111.957 .371,00$ & 116,62 & Sangat Efektif \\
2016 & $130.500 .000,00$ & $174.877 .932,00$ & 134,00 & Sangat Efektif \\
2017 & $200.500 .000,00$ & $235.739 .188,00$ & 117,57 & Sangat Efektif \\
& & Rata-rata & 90,40 & Efektif \\
\hline
\end{tabular}

Sumber : Data Diolah, 2018 
Berdasarkan Tabel 4 dapat dilihat tingkat efektivitas Pajak Hotel tahun 2013-2017. Selama kurun waktu lima tahun realisasi pemungutan Pajak Hotel terus meningkat setiap tahunnya. Ditahun 2013 tidak efektif dengan persentase sebesar 56,44\%. Pada tahun 2014 menurun hingga 27,40\% dengan kriteria tidak efektif. Pada tahun 2015 terjadi peningkatan yang signifikan hingga mencapai 116,62\% dengan kriteria sangat efektif, Pada tahun 2016 meningkat kembali menjadi 134,00\% dan ditahun 2017 terjadi penurunan yaitu sebesar $117,57 \%$. Jadi melihat data yang ada maka jumlah rata-rata dari penerimaan Pajak Hotel di Kota Tomohon selama tahun 2013-2017 adalah sebesar 90,40\% dengan kriteria efektif. Hal ini menunjukkan realisasi penerimaan Pajak Hotel di Kota Tomohon mengalami fluktuasi diikuti dengan terjadinya peningkatan target penerimaan Pajak Hotel. Pada tahun 2014 pemerintah menetapkan target hingga Rp324.365.000,00 sedangkan ditahun 2013 target yang ditetapkan sebesar Rp150.975.000,00, akibatnya realisasi penerimaan tidak mencapai target dengan tingkat efektivitas yang ikut menurun sebesar 27,40\% dengan kriteria tidak efektif. Tahun 2015 pemerintah menurunkan target Pajak Hotel dan realisasi penerimaan Pajak Hotel semakin meningkat, dalam hal ini melebihi target yang telah dianggarkan. Dengan kebijakan pemerintah yang menurunkan target Pajak Hotel dan penerimaan Pajak Hotel yang semakin meningkat ditahun berikutnya, penerimaan Pajak hotel dari tahun 2015-2017 menunjukkan kriteria efektif.

\section{Efektivitas Pemungutan Pajak Restoran Kota Tomohon Tahun 2013-2017}

Tabel 5. Efektivitas Penerimaan Pajak Restoran Kota Tomohon Tahun 2013-2017

\begin{tabular}{llcrl}
\hline Tahun & \multicolumn{1}{c}{$\begin{array}{c}\text { Target } \\
(\mathbf{R p})\end{array}$} & $\begin{array}{c}\text { Realisasi } \\
(\mathbf{R p})\end{array}$ & $\begin{array}{c}\text { Persentase } \\
(\boldsymbol{\%})\end{array}$ & Kriteria \\
\hline 2013 & $1.175 .000 .000,00$ & $1.484 .959 .553,00$ & 126,37 & Sangat Efektif \\
2014 & $1.227 .600 .000,00$ & $2.140 .442 .860,00$ & 174,35 & Sangat Efektif \\
2015 & $1.858 .600 .000,00$ & $3.019 .391 .763,00$ & 162,45 & Sangat Efektif \\
2016 & $3.087 .232 .000,00$ & $3.451 .597 .137,00$ & 111,80 & Sangat Efektif \\
2017 & $3.647 .232 .000,00$ & $3.263 .185 .687,00$ & 89,47 & Cukup Efektif \\
& & Rata-rata & 132,94 & Sangat Efektif \\
\hline
\end{tabular}

Sumber : Data Diolah, 2018

Berdasarkan Tabel 5 dapat dilihat tingkat efektivitas Pajak Restoran tahun 2013-2017. Ditahun 2013 tingkat efektivitas pajak restoran menunjukkan kriteria sangat efektif dengan persentase sebesar 126,37\%. Pada tahun 2014 mencapai 174,35\% sangat efektif. Pada tahun 2015 terjadi penurunan hingga 116,62\% dengan kriteria sangat efektif, Pada tahun 2016 tingkat efektivitas Pajak Restoran kembali menurun menjadi 111,80\% dan ditahun 2017 terjadi penurunan hingga $89,47 \%$ dengan kriteria cukup efektif. Jadi melihat data yang ada maka jumlah rata-rata dari penerimaan Pajak Hotel di Kota Tomohon selama tahun 20132017 adalah sebesar 132,94\% dengan kriteria sangat efektif. Hal ini menunjukkan bahwa Pemerintah Kota Tomohon sudah sangat efektif dalam mengelolah Pajak Restoran tapi pemungutan Pajak Restoran tiga tahun terakhir terus mengalami penurunan. Pemerintah Kota Tomohon juga harus melakukan pendataan kepada wajib pajak dengan turun langsung kelapangan/lokasi dan Pemerintah yang ada juga harus mampu memperbaiki pelaksanaan pemungutan Pajak Restoran khususnya dalam pemungutan terhadap setiap wajib pajak agar dapat memaksimalkan penerimaan Pajak Restoran lebih dari yang didapatkan saat ini serta dapat mempertanggungjawabkan penerimaan Pajak Restoran secara keseluruhan. Dengan hal ini maka wajib pajak bahkan masyarakat selaku subjek pajak juga dapat menyadari bahwa pentingya membayar pajak sehingga pada tahun selanjutnya penerimaan dan pendapatan Pajak Restoran semakin meningkat. 
Kontribusi Pajak Hotel Terhadap Pendapatatan Asli Daerah Kota Tomohon Tahun 2013-2017

Tabel 6. Kontribusi Pajak Hotel Terhadap Pendapatan Asli Daerah Kota Tomohon Tahun 2013-2017

\begin{tabular}{rrrrr}
\hline Tahun & $\begin{array}{c}\text { Realisasi Pajak } \\
\text { Hotel (Rp) }\end{array}$ & Realisasi PAD $(\mathbf{R p )}$ & $\begin{array}{r}\text { Persentase } \\
(\boldsymbol{\%})\end{array}$ & Kriteria \\
\hline 2013 & $85.216 .000,00$ & $13.945 .339 .275,00$ & 0,60 & Sangat Kurang \\
2014 & $88.875 .750,00$ & $17.378 .569 .341,00$ & 0,50 & Sangat Kurang \\
2015 & $11.957 .371,00$ & $20.688 .883 .680,00$ & 0,54 & Sangat Kurang \\
2016 & $174.877 .932,00$ & $26.321 .670 .690,00$ & 0,65 & Sangat Kurang \\
2017 & $235.739 .188,00$ & $29.543 .783 .344,00$ & 0,80 & Sangat Kurang \\
& & Rata-rata & 0.60 & Sangat Kurang \\
\hline
\end{tabular}

Sumber : Data Diolah, 2018

Berdasarkan Tabel 6 dapat dilihat kontribusi Pajak Hotel terhadap Pendapatan Asli Daerah (PAD) Kota Tomohon pada tahun 2013-2017. Kontribusi tahun 2013 sebesar 0,06\% dari penerimaan PAD sebesar Rp.13.945.339.275,00. Tahun 2014 meningkat hingga mencapai 0,50\% dari penerimaan PAD sebesar Rp.17.378.569.341,00. Tahun 2015 kontribusi Pajak Hotel menurun menjadi 0,54\% dari penerimaan PAD sebesar Rp.20.688.883.680,00, pada tahun 2016 sebesar 0,65\% dari penerimaan PAD sebesar Rp.26.321.670.690,00, tahun 2017 memberikan kontribusi sebesar $0,80 \%$ dari penerimaan PAD sebesar Rp.29.543.783.344,00. Jika berdasarkan pada kriteria kontribusi, maka kontribusi Pajak Hotel pada tahun 2013 adalah Sangat Kurang, tahun 2014 Sangat Kurang, tahun 2015 Sangat Kurang, tahun 2016 Sangat Kurang dan untuk tahun 2017 adalah Sangat Kurang.

Hal ini menunjukkan bahwa kontribusi Pajak Hotel di Kota Tomohon masih sangat kurang, maka perlu adanya peran dari Pemerintah Kota Tomohon untuk lebih meningkatkan pemungutan Pajak Hotel agar kontribusi yang diberikan lebih meningkat di tahun selanjutnya. Jumlah hotel yang ada di Kota Tomohon juga mempengaruhi kontribusi Pajak Hotel terhadap Pendapatan Asli Daerah. Walaupun memiliki banyak objek wisata, tetapi hotel yang ada di Kota Tomohon tergolong sedikit dan hotel-hotel yang didirikan memiliki kurang dari 200 kamar yang tergolong dalam kategori small hotel. Salah satu faktor penghambat yang menyebabkan rendahnya penerimaan pajak hotel adalah data yang tidak akurat dengan kondisi yang ada dilapangan. Dengan adanya kerjasama yang baik antara pihak-pihak terkait dalam pelaksanaan pemungutan dan pengelolaan Pajak Hotel diharapkan mampu mengoptimalkan kontribusi Pajak Hotel terhadap Pendapatan Asli Daerah Kota Tomohon. 
Kontribusi Pajak Restoran Terhadap Pendapatatan Asli Daerah Kota Tomohon Tahun 2013-2017

Tabel 7. Kontribusi Pajak Restoran Terhadap Pendapatan Asli Daerah Kota Tomohon Tahun 2013-2017

\begin{tabular}{llrrr}
\hline Tahun & $\begin{array}{c}\text { Realisasi Pajak } \\
\text { Restoran }(\mathbf{R p})\end{array}$ & Realisasi PAD $(\mathbf{R p )}$ & $\begin{array}{r}\text { Persentase } \\
(\boldsymbol{\%})\end{array}$ & Kriteria \\
\hline 2013 & $1.484 .959 .553,00$ & $13.945 .339 .275,00$ & 10,64 & Kurang Baik \\
2014 & $2.140 .442 .860,00$ & $17.378 .569 .341,00$ & 12,30 & Kurang Baik \\
2015 & $3.019 .391 .763,00$ & $20.688 .883 .680,00$ & 14,60 & Kurang Baik \\
2016 & $3.451 .597 .137,00$ & $26.321 .670 .690,00$ & 13,10 & Kurang Baik \\
2017 & $3.263 .185 .687,00$ & $29.543 .783 .344,00$ & 11,04 & Kurang Baik \\
& & Rata-rata & 12,33 & Kurang Baik \\
\hline
\end{tabular}

Sumber : Data Diolah, 2018

Berdasarkan Tabel 7 kontribusi Pajak Restoran terhadap PAD Kota Tomohon pada tahun 2013-2017. Kontribusi tahun 2013 sebesar 10,64\% dari penerimaan PAD sebesar Rp.13.945.339.275,00. Tahun 2014 meningkat hingga mencapai 12,30\% dari penerimaan PAD sebesar Rp.17.378.569.341,00.Tahun 2015 kontribusi Pajak Restoran meningkat kembali mencapai 14,60\% dari penerimaan PAD sebesar Rp.20.688.883.680,00, tahun 2016 memberikan kontribusi sebesar 13,10\% dari penerimaan PAD sebesar Rp.26.321.670.690,00, tahun 2017 memberikan kontribusi sebesar 11,04\% dari penerimaan PAD sebesar Rp.29.543.783.344,00. Jika berdasarkan pada kriteria kontribusi, maka kontribusi Pajak Restoran tahun 2013 adalah Kurang Baik, tahun 2014 Kurang Baik, tahun 2015 Kurang Baik, tahun 2016 Kurang Baik dan untuk tahun 2017 adalah Kurang Baik.

Hal ini menunjukkan bahwa kontribusi Pajak Restoran di Kota Tomohon masih kurang baik, maka perlu adanya peran dari Pemerintah Kota Tomohon untuk lebih memaksimumkan pemungutan Pajak Restoran. Salah satu faktor yang mempengaruhi besarnya tingkat kontribusi Pajak Restoran adalah terjadinya pertambahan jenis pajak daerah diantaranya Pajak Bumi Bangunan Pedesaan Perkotaan. Pajak Bumi Bangunan Pedesaan Perkotaan dilaksanakan mulai tahun 2014 dan memberikan pengaruh yang cukup besar terhadap PAD Kota Tomohon Tahun 2013-2017, akibatnya kontribusi yang diberikan Pajak Bumi Bangunan Pedesaan Perkotaan Cukup Baik. Selain itu banyaknya subjek pajak yang belum memiliki bahkan tidak suka mengurus ijin usaha sehingga penerimaan kurang optimal dan kurangnya kesadaran dan kepatuhan dari wajib pajak (pemilik restoran) dalam membayar Pajak Restoran, hal ini juga menjadi faktor yang menghambat peningkatan pemungutan Pajak Restoran.

\section{KESIMPULAN DAN SARAN}

\subsection{Kesimpulan}

1. Efektivitas Pajak Hotel di Kota Tomohon selama tahun 2013-2017 dari hasil penelitian yang dilakukan sudah efektif. Dimana pada tahun 2013 tingkat persentase sebesar 56,44\% (Tidak Efektif), tahun 2014 dengan persentase 27,40\% (Tidak Efektif), tahun 2015 dengan persentase 116,62\% (Sangat Efektif), tahun 2016 dengan persentase 134,00\% (Sangat Efektif) dan untuk tahun 2017 dengan persentase 117,57\% (Sangat Efektif) dengan rata-rata $90,40 \%$.

2. Efektivitas Pajak Restoran di Kota Tomohon selama tahun 2013-2017 dari hasil penelitian sangat efektif. Dimana pada tahun 2013 tingkat persentase sebesar 126,37\% (Sangat Efektif), tahun 2014 dengan persentase 174,35\% (Sangat Efektif), tahun 2015 dengan persentase 162,45\% (Sangat Efektif), tahun 2016 dengan persentase 111,80\% 
(Sangat Efektif) dan untuk tahun 2017 dengan persentase 89,47\% (Cukup Efektif) dengan rata-rata $132,94 \%$.

3. Kontribusi yang diberikan Pajak Hotel terhadap Pendapatan Asli Daerah Kota Tomohon tahun 2013-2017 dengan rata-rata hanya 0,60\%. Jika berdasarkan kriteria atau klasifikasi maka kontribusi Pajak Hotel terhadap Pendapatan Asli Daerah Kota Tomohon penilaiannya adalah sangat kurang bahkan sangat memperihatinkan. Dengan artian bahwa Pemerintah Kota Tomohon kurang optimal dalam pengelolaan Pajak Hotel sebagai salah satu sumber keuangan daerah. Kurangnya jumlah hotel di Kota Tomohon merupakan penyebab kontribusi yang diberikan Pajak Hotel sangat kurang.

4. Kontribusi dalam penerimaan Pajak Restoran terhadap Pendapatan Asli Daerah Kota Tomohon tahun 2013-2017 dengan rata-rata sebesar 12,33\%. Jika berdasarkan kriteria atau klasifikasi maka kontribusi dari Pajak Restoran terhadap Pendapatan Asli Daerah Kota Tomohon penilaiannya adalah Kurang Baik. Hal ini disebabkan oleh kurangnya kesadaraan dan kepatuhan wajib pajak dan masih banyak pula wajib pajak yang belum memiliki bahkan tidak suka mengurus ijin usaha sehingga penerimaan kurang optimal. Walaupun penerimaan Pajak Restoran secara nominal memang sudah sangat baik terbukti dari realisasi penerimaan yang sudah melebihi target tetapi dengan adanya penambahan jenis pajak daerah yaitu Pajak Bumi Bangunan Pedesaan Perkotaan yang pemungutannya dilaksanakan mulai tahun 2014 berpengaruh besar terhadap Pendapatan Asli Daerah Kota Tomohon sehingga mempengaruhi kontribusi yang diberikan oleh Pajak Restoran.

\subsection{Saran}

1. Sebaiknya Pemerintah Kota Tomohon melakukan penyuluhan yang lebih intensif dan secara berkala kepada wajib pajak yang enggan untuk mengurus ijin usaha dan membayar pajak karena masih sedikit omset yang diterima agar wajib pajak mengetahui tentang pentingnya membayar pajak khususnya Pajak Hotel dan Pajak Restoran serta menjelaskan kepada mereka bahwa dana yang dipungut itu digunakan untuk membantu kepentingan daerah dengan meningkatkan pembangunan secara umum, dengan begitu wajib pajak menjadi termotivasi untuk membayar pajak sehingga efektivitas dan kontribusi Pajak Hotel dan Pajak Restoran terhadap Pendapatan Asli Daerah Kota Tomohon lebih meningkat.

2. Pemerintah Kota Tomohon harus memberikan sanksi tegas kepada wajib pajak yang tidak memenuhi kewajiban perpajakan sebagaimana mestinya.

3. Pemerintah Kota Tomohon diharapkan melakukan update atau pendataan ulang agar dapat mengumpulkan data objek-objek baru Pajak Hotel dan Pajak Restoran yang memiliki potensi untuk lebih meningkatkan penerimaan Pendapatan Asli Daerah dan juga bisa menjadi gambaran untuk penentuan target tahun selanjutnyaa.

4. Badan Keuangan Daerah Kota Tomohon diharapkan terus meningkatkan kinerjanya agar profesionalitas pekerjaan terus membaik dan tingkat efektivitas yang sudah baik tetap terus konsisten terlebih bisa meningkat.

\section{DAFTAR PUSTAKA}

Candrasari, Anita. 2015. Kontribusi Pajak Hotel dan Pajak Restoran Terhadap Peningkatan Pendapatan Asli Daerah Kota Surabaya. Skripsi. Sekolah Tinggi

Ilmu Ekonomi Indonesia (STIESIA). Surabaya.

Lubis, Irsan. 2015. Mahir Akuntansi Pajak Terapan. Andi. Yogyakarta.

Mahmudi. 2015. Manajemen Kinerja Sektor Publik. Edisi Kedua. Yogyakarta: UPP STIM YKPN.

Mardiasmo. 2013. Perpajakan Edisi Revisi. Andi. Yogyakarta.

Peraturan Daerah Kota Tomohon Nomor 7 tahun 2012 Pajak Daerah. 
Puspita, Devi. 2016. Analisis Efektivitas Penerimaan Pajak Restoran, Pajak Hotel, Dan Pajak Penerangan Jalan Dalam Meningkatkan Pendapatan Asli Daerah Kota Depok. Skripsi. Universitas Islam Negeri Syarif Hidayatullah. Jakarta.

Rooy. 2016. Analisis Kontribusi Penerimaan Pajak Daerah Terhadap Pendapatan Asli Daerah (PAD) di Kabupaten Raja Ampat. Jurnal EMBA Universitas Samratulangi Vol. 3, No.4 ISSN 2303-1174.

Sari, Diana. 2013. Konsep Dasar Perpajakan. Cetakan Pertama. Reflika Aditama. Bandung.

Simamora, Henry. 2013. Akuntansi Manajemen. Salemba Empat. Jakarta.

Sisdayani, Eka. 2013. Penilaian Kinerja Atas Penerimaan Pajak Hotel Dan Pajak Restoran Di Dinas Pendapatan Daerah Kabupaten Karangasem. Skripsi. Universitas Udayana. Bali.

Sujawerni, V. Wiratna. 2014. Metodologi Penelitian. Pustaka Baru, Yogyakarta.

Undang-Undang Republik Indonesia Nomor 28 Tahun 2009 Pajak Daerah dan Retribusi Daerah. Lembaran Negara Republik Indonesia Tahun 2009. Jakarta. 